\title{
Does IOR occur in discrimination tasks? Yes, it does, but later
}

\author{
JUAN LUPIÁÑEZ, EMILIO G. MILÁN, FRANCISCO J. TORNAY, \\ EDUARDO MADRID, and PÍO TUDELA \\ University of Granada, Granada, Spain
}

\begin{abstract}
When a stimulus appears in a previously cued location several hundred milliseconds after the cue, the time required to detect that stimulus is greater than when it appears in an uncued location. This increase in detection time is known as inhibition of return (IOR). It has been suggested that IOR reflects the action of a general attentional mechanism that prevents attention from returning to previously explored loci. At the same time, the robustness of IOR has been recently disputed, given several failures to obtain the effect in tasks requiring discrimination rather than detection. In a series of eight experiments, we evaluated the differences between detection and discrimination tasks with regard to IOR. We found that IOR was consistently obtained with both tasks, although the temporal parameters required to observe IOR were different in detection and discrimination tasks. In our detection task, the effect appeared after a 400-msec delay between cue and target, and was still present after 1,300 msec. In our discrimination task, the effect appeared later and disappeared sooner. The implications of these data for theoretical accounts of IOR are discussed.
\end{abstract}

Attention is widely presumed to play an important role in the rapid and efficient scanning of visual environments. In particular, when search is difficult, the movement of attention from one location to another may improve discrimination at each location, and thus also improve overall search efficiency. However, the efficiency of search also depends on the ability to prevent attention from returning to previously examined locations. This issue has been the focus of considerable study by attention researchers over the past decade.

Specifically, it has been shown that response to a target is speeded if the location at which the target appears is precued. In the cost-benefit paradigm (Posner, 1980), subjects are to respond to a target appearing in one of three boxes, one in the center of the screen and one to each side of the center. Before the target appears, the subject's attention is cued to one of the two peripheral locations. This attentional cuing is accomplished by making one of the two peripheral boxes flicker briefly. The target then appears in either the cued location (cued trials) or the uncued location (uncued trials). When the cue-target stimulus onset asynchrony (SOA) is less than about $300 \mathrm{msec}$, responses are faster on cued than on uncued trials.

\footnotetext{
We thank Steven P. Tipper, Bruce Milliken, Arthur F. Kramer, an anonymous reviewer, and especially Raymond Klein for their useful comments. Bruce Milliken also helped improve our English. Pilar Gonzalvo helped us with data collecting. We are grateful to all of them. This research was financially supported by the Spanish Ministerio de Educación y Ciencia (Grant PB931114 from the DGICYT to Francisco Martos, and by MEC FPI Grant AP92-24228372 to J.L.). Correspondence should be addressed to J. Lupiáñez Castillo, Departamento de Psicología Experimental y Fisiología del Comportamiento, Facultad de Psicología, Campus Universitario de Cartuja, Universidad de Granada, 18071-Granada, Spain (e-mail: jlupiane@platon.ugr.es).
}

However, Posner and Cohen (1984) demonstrated that at SOAs of longer than $300 \mathrm{msec}$, the opposite pattern of results is observed; that is, response times (RTs) become longer on cued than on uncued trials. They used the term inhibition of return (IOR) to describe the effect, arguing that "the inhibition effect evolved to maximize sampling of the visual environment" (p. 550).

Following this initial study, other researchers extended the effect to different dependent variables and tasks. Thus, IOR has now been reported using manual keypress (Posner \& Cohen, 1984) and eye movement latency (Abrams \& Dobkin, 1994; Pratt, 1995) as dependent variables, and with both target detection and localization tasks (Maylor, 1985). The effect has also been reported in both attentional cuing tasks (cue-target paradigm) and tasks requiring a response to the same location on consecutive trials (target-target paradigm; Maylor, 1985). Within attentional cuing tasks, IOR is usually obtained only when a peripheral (exogenous) attentional cue is used. However, Rafal, Calabresi, Brennan, and Sciolto (1989) reported IOR using a central arrow (endogenous) cue, if subjects prepared an eye movement in the direction indicated by the cue, even though they had "canceled" that preparation before target onset.

It has recently been argued that attention is inhibited to return not only to the location but also to the object in which the cue appears (Tipper, Weaver, Jerreat, \& Burak, 1994; but see Müller \& Mühlenen, 1996). Tipper et al. called the former effect "location-based" and the latter effect "object-based" IOR (Tipper, Driver, \& Weaver, 1991).

In summary, a good deal of experimental research suggests that IOR is a robust and general effect that demonstrates a general principle of information processing. However, the generality of the effect has been disputed recently 
on the grounds that it is limited to simple RT tasks (detection): "An IOR effect on choice RTs has been observed only in tasks requiring a saccadic or manual localization response" (Müller \& Mühlenen, 1996, p. 244).

In fact, several studies have failed to obtain IOR with choice RT tasks when target discrimination is necessary to respond. Egly, Rafal, and Henik (1992) and Terry, Valdes, and Neill (1994) used shape discrimination: Kingstone and Gazzaniga (1992, reported in Klein \& Taylor, 1994) and Tanaka and Shimojo (1996) used color discrimination; Pontefract and Klein (1988, reported in Klein \& Taylor, 1994), and Tanaka and Shimojo used size discrimination; and Tanaka and Shimojo used orientation, vernier, and luminance discrimination.

So far, only Pratt (1995) has reported IOR in a discrimination task. In Pratt's experiment, subjects were required to move their eyes toward and fixate a target event. Eye movement latency was used as the dependent variable. Therefore, even though the target was to be discriminated-because two stimuli were displayed (a target and a distractor)-a localization response was implied. Hence, it has not been established whether IOR occurs in discrimination tasks that do not require the subject to localize the target. Another important issue in this experiment is the fact that a longer-than-usual cue-target SOA was used $(960 \mathrm{msec})$.

In fact, we have obtained IOR with a choice RT task in our laboratory, but a $1,000-\mathrm{msec}$ SOA was necessary (Lupiáñez, 1996; Lupiáñez, Milán, Tornay, \& Tudela, 1996; Lupiáñez, Tornay, \& Tudela, 1996). For example, in one experiment, subjects were asked to discriminate the direction indicated by an arrow that was displayed in one of two boxes (to the left and right of fixation), one of which had previously been cued. Subjects responded by hitting one of two keys, depending on the direction of the arrow. Three different SOAs $(100,600$, and $1,000 \mathrm{msec})$ were used in this experiment, and their presentation was mixed within a block. Importantly, IOR was obtained only at the longest SOA of $1,000 \mathrm{msec}$. In another experiment, only the two shorter SOAs were used, and facilitation was observed for both. Thus, it appears that IOR may be obtained in discrimination tasks, but that it is observed at longer SOAs than during detection tasks. This hypothesis was tested directly in the series of experiments reported in this article.

A secondary issue addressed here concerns the fact that in discrimination tasks, a left-hand/right-hand response button assignment is customarily used to record a response to the target, and the target itself can appear in either the left or the right visual field. Thus, the stimulus can be displayed in the visual field either ipsilateral or contralateral to the hand of response. Ipsilateral responses are usually faster and more precise than contralateral responses. This effect is known as the Simon effect (Hommel, 1995; Simon, 1969; Simon \& Rudell, $1967)$ and has been discussed recently in relation to the orienting of attention (Umiltà \& Nicoletti, 1992). Given that IOR has been previously obtained only in detection tasks (a single response) and in localization tasks (only ipsilateral trials), the relation between IOR and the Simon effect has not been previously explored. Thus, the examination of IOR in discrimination tasks that do not involve localization of the target enabled us to examine the relation between IOR and the Simon effect.

In summary, previous research has challenged the robustness and generality of IOR, given that it has not been obtained reliably in discrimination tasks. In this work we explored the robustness of IOR with discrimination and detection tasks. Different SOAs were used across experiments to investigate the time course of IOR for both simple RT (detection) and choice RT (discrimination) tasks. Thus, the experiments differed only in the SOAs used and whether detection or discrimination responses were required.

\section{GENERAL METHOD}

\section{Subjects}

All subjects in these experiments were from the Faculty of Psychology of the University of Granada. Subjects were naive as to the purpose of the experiment and participated in exchange for course credit. A different group of 18 subjects participated in each of the eight main experiments, and all members within each group were tested simultaneously in a room equipped with 20 computers. A different group of 6 subjects participated in each of the two additional experiments (eye movement monitoring), and subjects were tested individually.

\section{Apparatus and Stimuli}

Stimuli were presented on a 14-in. color VGA monitor. An IBMcompatible 486/33 microcomputer running MEL software (Schneider, 1988) controlled the presentation of stimuli, timing operations, and data collection. Responses were made by pressing a key on the computer keyboard. When only one response was required (detection), subjects pressed the " $B$ " key with any finger. In the discrimination task, subjects pressed either the " $X$ " key (left response) with the index finger of the left hand or the " $\mathrm{M}$ " key (right response) with the index finger of the right hand. Subjects sat approximately $60 \mathrm{~cm}$ from the computer monitor.

\section{Procedure}

The target on each trial appeared in the center of one of two boxes, displayed to the left and right of fixation. The boxes remained on the screen throughout each trial and disappeared only between trials. The boxes subtended $17 \mathrm{~mm}$ in height $\times 14 \mathrm{~mm}$ in width $\left(1.62^{\circ}\right.$ and $1.33^{\circ}$ of visual angle at a viewing distance of 60 $\mathrm{cm})$. The inner edge of each box was $77 \mathrm{~mm}\left(7.31^{\circ}\right)$ from the fixation point (the plus sign [+], displayed in white). The target to be detected or discriminated was a colored asterisk, which was either red or yellow with equal probability. The boxes were displayed in dark gray on a black background. On every trial, at varying temporal intervals before presentation of the target, one of the two boxes was presented in white for $50 \mathrm{msec}$ before returning to its original dark gray. This increase in luminance gave the impression of a brief flicker. This flicker is referred to hereafter as the "attentional cue."

The sequence of events on each trial is depicted in Figure 1. A fixation point was displayed together with the two boxes for 1,000 msec. Then one of the two boxes flickered for $50 \mathrm{msec}$. Following the flicker, the fixation point and the boxes remained on the screen for $50,350,650,950$, or $1,250 \mathrm{msec}$, depending on the SOA for that trial. Following this interval, the target was displayed for $33 \mathrm{msec}$, and then the fixation point and boxes were again displayed alone until the subject's response, or for a maximum of $2,000 \mathrm{msec}$. If no response was made within $2,000 \mathrm{msec}$, the next trial began. The in- 


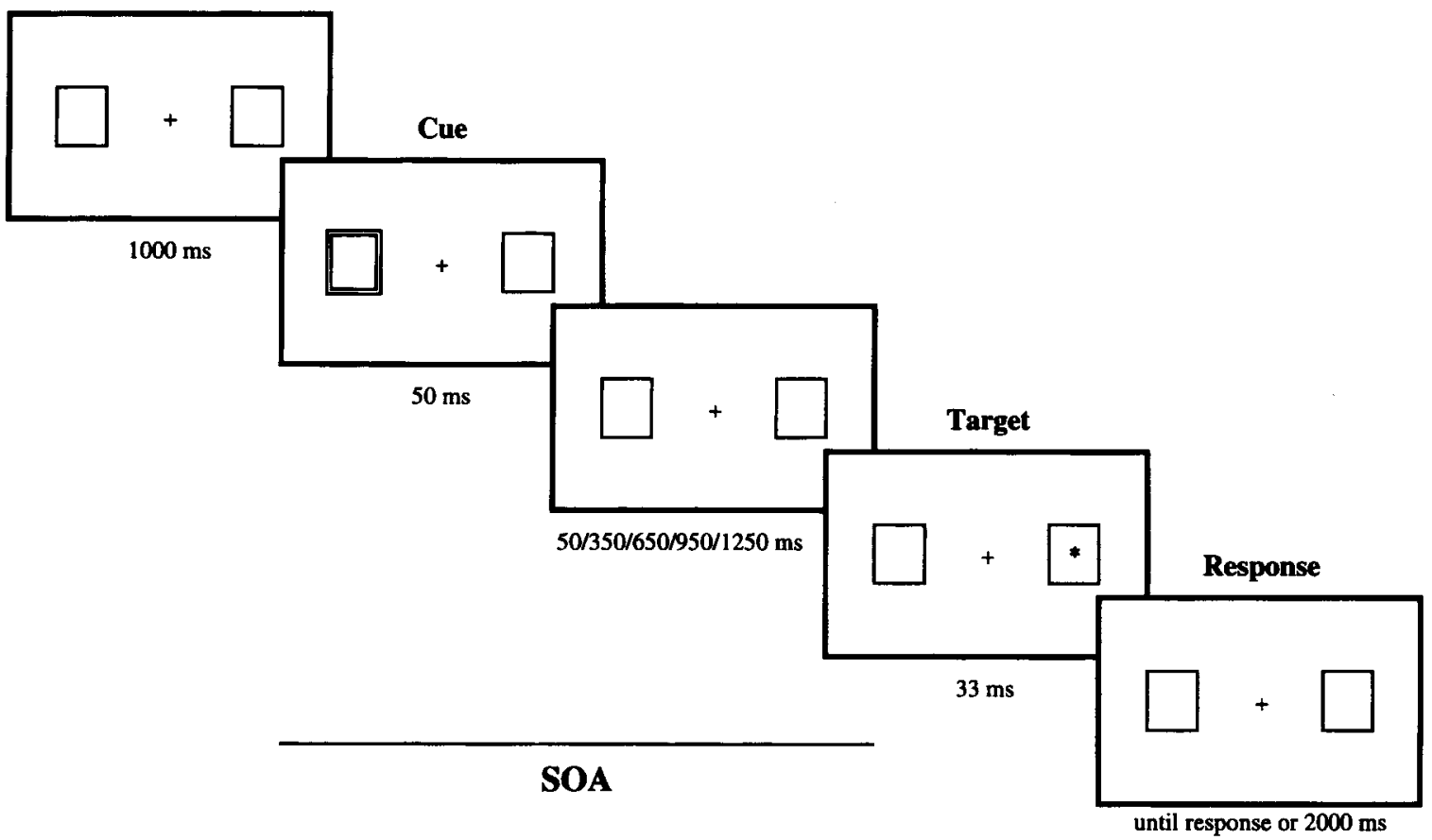

Figure 1. Experiment trial sequence, from top left to bottom right. Each trial began with a fixation point and two boxes displayed in gray for 1,000 msec. Then one of the two boxes was displayed in white for 50 msec. After 50, 350, 650, 950, or 1,250 msec (depending on the stimulus onset asynchrony), the target, a red or yellow asterisk, was displayed for 33 msec. Then the fixation point and the two boxes were again displayed in gray, either until subject's response or for 2,000 msec if no response was made.

terval between trials was $1,000 \mathrm{msec}$ in duration, and the screen remained black throughout this interval.

The response required of subjects depended on the task. In the detection task, subjects were given instructions to press the " $B$ " key if, and only if, an asterisk appeared, and regardless of the color of the asterisk. In the discrimination task, half of the subjects were to press the " $X$ " key when the asterisk was yellow and the " $M$ " key when it was red, and the other half were to do the opposite-press the "X" key for red and the "M" key for yellow. In both tasks, the target was absent on $20 \%$ of the trials (catch trials), in which case subjects were simply required to wait for the beginning of the next trial. Auditory feedback (a $400-\mathrm{Hz}$ computer-generated tone of 100 msec) was provided on error trials.

Trials were grouped in blocks of 100 and presented randomly within each block. The experiment was interrupted for 1 min every 50 trials to allow the subject to rest. Subjects were instructed to press the space bar to continue the experimental session after each rest period.

\section{Design}

Two independent variables were orthogonally manipulated in each block of trials: cuing and SOA. Cuing took two values: The target could appear either in the cued box (cued trial) or in the uncued box (uncued trial). In each experiment, a 100-msec SOA was paired with another, longer, one-100 and $400 \mathrm{msec}$ in Experiment 1,100 and $700 \mathrm{msec}$ in Experiment 2,100 and 1,000 $\mathrm{msec}$ in Experiment 3, and 100 and 1,300 msec in Experiment 4. In the discrimination task, because the target could be responded to with either the left or the right hand, and could also appear in the left or the right box, there were two kinds of trials-ipsilateral and contralateral. This variable was called "stimulus-response location compatibility" and was also completely crossed in any block of trials.
In the detection task (only one central response), this variable had no meaning and was dummy coded. Given that all the independent variables were completely crossed within each block and that all variables took any value with the same probability (apart from catch vs. experimental trials), there was no predictive relation between the attentional cue and the target's location or color. Similarly, there was temporal uncertainty.

In each experiment, subjects performed one practice block and two blocks of experimental trials. The practice block consisted of four trials of each combination of compatibility (2) $\times$ cuing $(2) \times$ SOA (2), and eight catch trials $(32+8=40$ trials). Each block of experimental trials consisted of 10 trials of every combination and 20 catch trials $(80+20=100$ trials $)$. Thus, the experimental condition consisted of 200 trials, 160 of which represented the 20 replications of each of eight different trial types, and 40 of which were catch trials.

\section{EXPERIMENTS 1A-1B 100- and 400-msec SOAs}

Two SOAs were used in these experiments: 100 and $400 \mathrm{msec}$. The two experiments differed only in terms of the response given to the target. In Experiment 1A, subjects were required to detect the target, whereas in Experiment $1 \mathrm{~B}$, subjects were required to discriminate its color. However, because subjects used left- and right-hand responses to record their color discrimination, location compatibility was meaningful as an independent variable in Experiment 1B, but not in Experiment 1A. Thus, results of these two experiments are reported separately. 


\section{Results}

Rates of false alarms (responses to catch trials) ${ }^{1}$ were 0.061 and 0.050 (for short and long SOAs, respectively) in Experiment $1 \mathrm{~A}$ and 0.047 and 0.036 in Experiment 1B. Trials with correct responses faster than $100 \mathrm{msec}$ or slower than $1,200 \mathrm{msec}$ ( $1.04 \%$ of correct response trials), as well as incorrect responses, were excluded from the RT analysis. Mean RTs and percent errors ${ }^{2}$ are shown in Tables 1 and 2.

Experiment 1A: Detection task. Mean RTs of correct responses were introduced into a repeated measures analysis of variance (ANOVA) with SOA (2 levels) and cuing ( 2 levels) ${ }^{3}$ as independent variables. This analysis revealed a significant interaction between SOA and cuing $\left[F(1,17)=21.26, M S_{\mathrm{e}}=456.38, p<.001\right]$. Further analysis of the interaction revealed a facilitation effect at the short $(21 \mathrm{msec}) \mathrm{SOA}$; cued trials were responded to faster than uncued ones $[F(1,17)=8.57$, $\left.M S_{\mathrm{e}}=449.14, p<.01\right]$, and an IOR effect at the long SOA $\left[F(1,17)=15.94, M S_{\mathrm{e}}=374.47, p<.001\right]$. Also, RTs in cued trials were significantly shorter at the short $(381-\mathrm{msec})$ than at the long $(402-\mathrm{msec}) \mathrm{SOA}[F(1,17)=$ $\left.16.97, M S_{\mathrm{e}}=445.01, p<.001\right]$. The opposite was true for uncued trials: RTs were slower at the short SOA [410 vs. $\left.384 \mathrm{msec} ; F(1,17)=8.37, M S_{\mathrm{e}}=328.15, p<.05\right]$. Thus, the usual IOR effect (i.e., slower responses to the cued than to the uncued location) was observed with the detection procedure.

Analysis of error percentages revealed no significant effects.

Experiment 1B: Discrimination task. Mean RTs for correct responses in the discrimination task were submitted to a repeated measures ANOVA, with compatibility ( 2 levels), SOA (2 levels), and cuing (2 levels) treated as independent variables. This analysis revealed a significant main effect of cuing $[F(1,17)=19.27$, $M S_{\mathrm{e}}=2,945.6, p<.001$ ], showing faster responses in cued than in uncued trials $(40 \mathrm{msec})$. There were no other significant effects in the analysis (all $p \mathrm{~s}>.15$ ).

The analysis of error percentages revealed a main effect of cuing $\left[F(1,17)=10.43, M S_{\mathrm{e}}=131.79, p<.01\right]$ : Responses on cued trials ( $6 \%$ errors) were more accurate than responses on uncued trials (12\% errors). Also, cuing interacted with SOA $\left[F(1,17)=7.85, M S_{\mathrm{e}}=124.36\right.$, $p<.05]$. F'irther analysis revealed that the cuing effect was significant only at the longer SOA $[F(1,17)=9.64$, $\left.M S_{\mathrm{e}}=242.07, p<.01\right]$.

Separate analyses of misses (no response) and mistakes (incorrect response) showed the same results: a facilitation effect at the longer SOA for both misses $[4.6 \% ; F(1,17)=$ $\left.10.04, M S_{\mathrm{e}}=37.68, p<.01\right]$ and mistakes $[6.8 \% ; F(1,17)$ $\left.=7.77, M S_{\mathrm{e}}=107.21, p<.02\right]$.

\section{Discussion}

Experiments 1A-B differed only in the response that subjects made to the target. When subjects were required to detect the target, a facilitation effect was observed at the 100-msec SOA, and the opposite was observed at the 400-msec SOA, thus demonstrating the usual IOR pattern (Posner \& Cohen, 1984). However, when subjects were required to discriminate the target's color, a facilitation effect was observed at both the 100- and 400-msec SOAs. In fact, a subsequent ANOVA that treated task (detection/discrimination) as a between-subjects variable revealed a significant three-way interaction between task, cuing, and SOA $\left[F(1,34)=7.4, M S_{\mathrm{e}}=430, p<.02\right]$. Thus, the cuing $\times$ SOA interaction was indeed modulated by differences inherent in the detection and discrimination tasks.

The data from these experiments support previous reports of failure to demonstrate IOR in a discrimination task (Pontefract \& Klein, 1988, reported in Klein \& Taylor, 1994; Terry et al., 1994). Pontefract and Klein used two similar values of SOA (100 and $500 \mathrm{msec})$ in separate blocks of trials and obtained similar results: When a choice RT task was used, facilitation was observed at both SOAs. However, when a simple RT task was used, facilitation was observed at the $100-\mathrm{msec}$ SOA and IOR was observed at the 500-msec SOA.

Thus, the effect of cuing a location appears to have different effects depending on the nature of the task. At short SOAs, cuing appears to benefit both detection and discrimination of the target. However, at longer SOAs (400 msec here, $500 \mathrm{msec}$ in Pontefract and Klein, 1988), cuing appears to help discrimination but hinder detection.

Given the lack of IOR in such discrimination tasks, many researchers have argued against the notion that IOR is a robust and general effect (Terry et al., 1994) and against its attentional nature (Klein \& Taylor, 1994; Schmidt, 1996). Terry and colleagues argued that if IOR reflects an innate principle of attentional processing, namely preventing attention from returning to recently attended locations, then the effect should be obtained with any task. However, given that the effect is sensitive to changes in task, IOR may not reflect a general principle of information processing, but rather a specific mechanism that is relevant for some types of information processing but not for others. Others have argued that if IOR were the opposite of the facilitative effect observed at short SOAs (i.e. attentional inhibition), then IOR ought to be observed in all tasks that demonstrate such facilitation effects. However, given that IOR has been observed reliably only in tasks requiring target detection or localization, it has been argued that IOR may be associated with responding (Klein \& Taylor, 1994) or with the visualmotor action system, rather than with attention (but see Reuter-Lorenz, Jha, \& Rosenquist, 1996, for an attentional conception of IOR).

As we noted in the introduction, the IOR effect might occur in both detection and discrimination tasks, yet with different temporal parameters. The following experiments were conducted to explore whether the same dissociation regarding IOR between detection and discrimination tasks would be obtained with longer SOAs. 

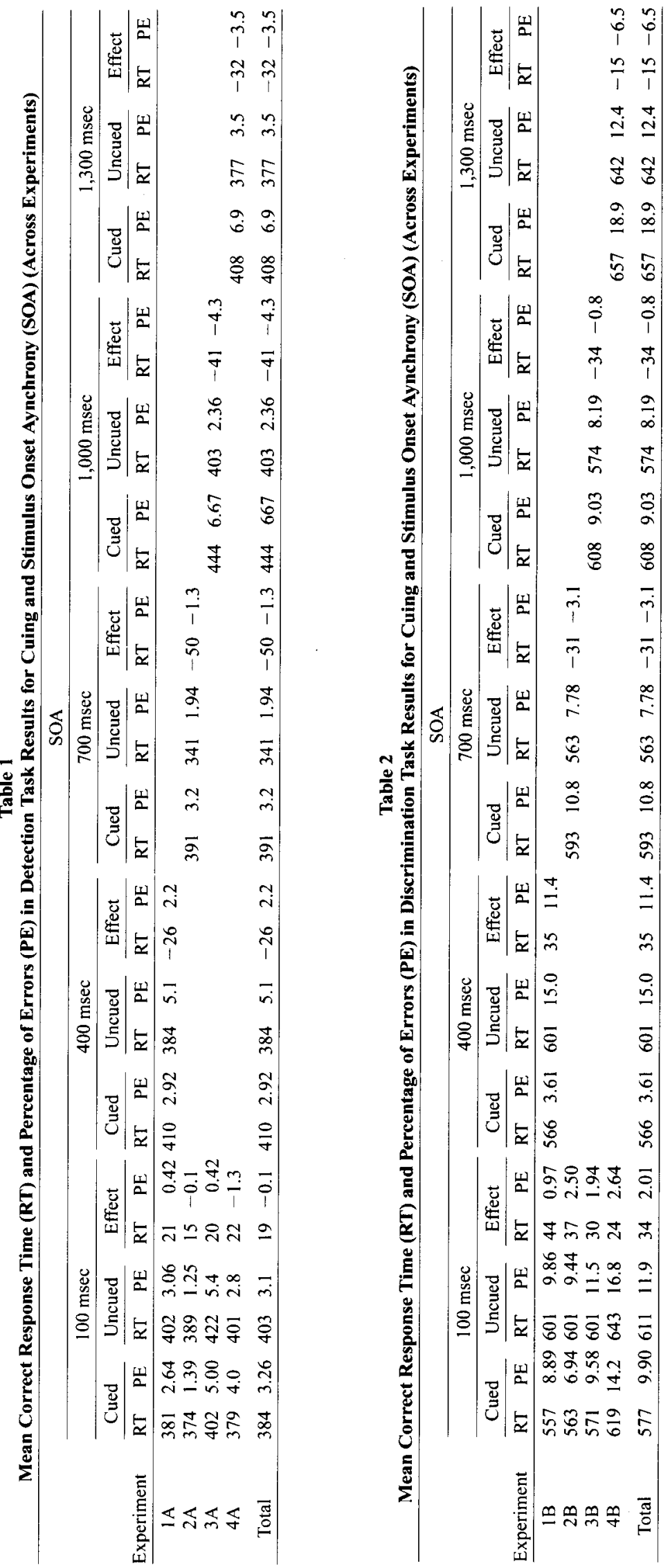


\section{EXPERIMENTS 2A-2B}

\section{0- and 700-msec SOA}

The SOAs used in this experiment were 100 and $700 \mathrm{msec}$. Apart from this change, the method was the same as in the previous experiments.

\section{Results}

Rates of false alarms (responses to catch trials) were 0.064 and 0.036 (for short and long SOAs, respectively) in Experiment 2A and 0.019 and 0.011 in Experiment 2B. Trials with correct responses faster than $100 \mathrm{msec}$ or slower than $1,200 \mathrm{msec}(0.91 \%$ of correct response trials), as well as incorrect responses, were excluded from the RT analysis. Mean RTs and percent errors are shown in Tables 1 and 2.

Experiment 2A: Detection task. Mean RTs for correct responses were submitted to a repeated measures ANOVA with SOA and cuing treated as independent variables. There were two significant effects: the main effect of cuing $\left[F(1,17)=12.44, M S_{\mathrm{e}}=431.2, p<.01\right]$ and the SOA $\times$ cuing interaction $\left[F(1,17)=44.23, M S_{\mathrm{e}}=\right.$ $430.6, p<.0001]$. To interpret this interaction, the effect of cuing was examined separately at each SOA. Both the facilitation effect at the short $(15-\mathrm{msec}) \mathrm{SOA}$ and the IOR effect at the 700-msec SOA ( $-50 \mathrm{msec})$ were significant $\left[F(1,17)=15.56, M S_{\mathrm{e}}=134.71, p<.002\right.$, and $F(1,17)=$ $30.69, M S_{\mathrm{e}}=727.11, p<.0001$, respectively]. Responses to uncued trials were significantly shorter at the long SOA $\left(341\right.$ vs. $389 \mathrm{msec} ; F(1,17)=51.2, M S_{e}=399.4$, $p<.0001]$.

Analysis of error percentages revealed a significant effect of SOA $\left[F(1,17)=4.93, M S_{\mathrm{e}}=5.7, p<.05\right]$-more errors took place at the longer SOA. The main effect of cuing was marginally significant $\left[F(1,17)=3.57, M S_{\mathrm{e}}=\right.$ $2.43, p=.076$ ] due to a larger percentage of errors in cued trials.

Experiment 2B: Discrimination task. Mean RTs for correct responses in the discrimination task were submitted to a repeated measures ANOVA, with compatibility, SOA, and cuing treated as independent variables. Only the SOA $\times$ cuing interaction was significant $\left[F(1,17)=37.34, M S_{\mathrm{e}}=1,114.4, p<.0001\right]$. To interpret the interaction, the cuing effects were analyzed separately at each SOA. Both the facilitation effect ( 38 $\mathrm{msec})$ at the shorter SOA and the IOR effect $(-30 \mathrm{msec})$ at the longer SOA were significant $[F(1,17)=23.01$, $M S_{\mathrm{e}}=1,092.81, p<.001$, and $F(1,17)=21.27, M S_{\mathrm{e}}=$ $793.59, p<.001$, respectively]. At the longer SOA, there was an increase in RT in cued trials $[30 \mathrm{msec} ; F(1,17)=$ $\left.12.68, M S_{\mathrm{e}}=1,298.19, p<.01\right]$ and a decrease in uncued trials $\left[38 \mathrm{msec} ; F(1,17)=16.46, M S_{\mathrm{e}}=1,559.13\right.$, $p<.001]$. No other effect or interaction was significant.

Analysis of error percentages revealed a similar pattern of results. Again, only the SOA $\times$ cuing interaction was significant $\left[F(1,17)=8.25, M S_{\mathrm{e}}=49.22, p<.02\right]$. There was a significant facilitation effect at the short SOA $\left(2.5 \%\right.$ errors; $F(1,17)=8.5, M S_{\mathrm{e}}=13.23, p<$
$.01]$. Although the IOR effect was not significant, it was consistent with that of the RTs $(-3.1 \%$ errors).

The SOA $\times$ cuing interaction was also significant in the mistakes analysis $\left[F(1,17)=4.98, M S_{\mathrm{e}}=27.29, p<\right.$ $.05]$. No other effect was significant in the analysis of either mistakes or misses.

\section{Discussion}

In Experiments 1A-1B, an IOR effect was observed only in the detection task. Although the only difference between those experiments and Experiments $2 \mathrm{~A}-2 \mathrm{~B}$ was the change of the longer SOA to $700 \mathrm{msec}$, the pattern of results was quite different. Here, the IOR effect appeared not to depend on the task, being significant at the longer SOA in both detection and discrimination tasks $(-50$ and $-31 \mathrm{msec}$, respectively). It is worth noting here that the three-way interaction between task, SOA, and cuing, which proved significant across Experiments $1 \mathrm{~A}-1 \mathrm{~B}$, did not approach significance across Experiments $2 \mathrm{~A}-2 \mathrm{~B}(p>.8)$. Therefore, these results contradict previous claims that IOR is limited to detection and localization tasks (Klein \& Taylor, 1994; Terry et al., 1994). This experiment shows clearly that the same pattern of results can be obtained in detection and discrimination tasks when a longer SOA is used.

Two further experiments were conducted, with two aims. First, we deemed it important to replicate the IOR effect in discrimination. Second, we wanted to further examine the temporal course of IOR in the two tasks. In detection tasks, IOR has been reported at $1,000 \mathrm{msec}$ and longer SOAs (Reuter-Lorenz et al., 1996). The following experiment tested whether this also occurs in discrimination tasks.

\section{EXPERIMENTS 3A-3B 100- and 1,000-msec SOAs}

Two different SOAs were used in this experiment (100 and $1,000 \mathrm{msec}$ ). Apart from this change, the method was the same as in the previous experiments.

\section{Results}

Rates of false alarms (responses to catch trials) were 0.008 and 0.006 (for short and long SOAs, respectively) in Experiment $3 \mathrm{~A}$ and 0.028 and 0.014 in Experiment 3B. Trials with correct responses faster than $100 \mathrm{msec}$ or slower than $1,200 \mathrm{msec}(0.88 \%$ of correct response trials), as well as incorrect responses, were excluded from the RT analysis. Mean RTs and percent errors are shown in Tables 1 and 2.

Experiment 3A: Detection task. Mean RTs for correct responses were submitted to a repeated measures ANOVA, with SOA and cuing treated as independent variables. The main effect of cuing was significant $[F(1,17)=$ $\left.7.46, M S_{\mathrm{e}}=280.3, p<.05\right]$, as well as the SOA $\times$ cuing interaction $\left[F(1,17)=81.64, M S_{\mathrm{e}}=202.6, p<.001\right]$. Further analysis of the interaction revealed a significant facilitation effect at the shorter $(20-\mathrm{msec}) \operatorname{SOA}[F(1,17)=$ 
11.98, $\left.M S_{\mathrm{e}}=286.6, p<.01\right]$, and IOR at the longer $(-41 \mathrm{msec})$ SOA $\left[F(1,17)=77.5, M S_{\mathrm{e}}=196.06, p<\right.$ $.001]$. RT in cued trials was significantly faster at the shorter $(402-\mathrm{msec})$ than at the longer (444-msec) SOA $\left[F(1,17)=28.68, M S_{\mathrm{e}}=551.71, p<.001\right]$. For uncued trials, the opposite result was obtained ( $422 \mathrm{msec}$ for the short SOA vs. $403 \mathrm{msec}$ for the long SOA), but it was only marginally significant $\left[F(1,17)=3.75, M S_{\mathrm{e}}=839.38\right.$, $p=.0695]$. Again, the usual facilitation and IOR effects were replicated with the detection task.

Analysis of error percentages also revealed a significant main effect of cuing $\left[F(1,17)=7.21, M S_{\mathrm{e}}=9.49\right.$, $p<.01]$ and a significant interaction between SOA and cuing $\left[F(1,17)=5.11, M S_{\mathrm{e}}=19.65, p<.05\right]$. Responses to cued trials were less precise than those to uncued trials $(5.82 \%$ vs. $3.89 \%$ errors $)$, and the pattern of the interaction for errors was similar to that for the RTs. Indeed, the IOR effect at the $1,000-\mathrm{msec}$ SOA $(-4.32 \%)$ was significant $\left[F(1,17)=12.66 M S_{\mathrm{e}}=13.16, p<.01\right]$.

Experiment 3B: Discrimination task. Mean RTs for correct responses in the discrimination task were submitted to a repeated measures ANOVA, with compatibility, SOA, and cuing treated as independent variables. This analysis revealed a significant SOA $\times$ cuing interaction $\left[F(1,17)=35.83, M S_{\mathrm{e}}=1,017.0, p<.001\right]$. The SOA $\times$ compatibility $\times$ cuing interaction was also significant $\left[F(1,17)=14.08, M S_{\mathrm{e}}=445.7, p<.01\right]$.

We followed two strategies to unpack the interaction: First, even though the SOA $\times$ cuing interaction was significant for both ipsilateral $\left[F(1,17)=8.9, M S_{\mathrm{e}}=701.2\right.$, $p<.01]$ and contralateral trials $\left[F(1,17)=47.9, M S_{\mathrm{e}}=\right.$ $761.53, p<.001]$, both effects (facilitation and IOR) were larger for contralateral ( 42 and $-48 \mathrm{msec}$, respectively) than for ipsilateral trials (18 and $-19 \mathrm{msec}$, respectively). The IOR effect was significant for both ipsilateral trials $\left[F(1,17)=5.21, M S_{\mathrm{e}}=625.6, p<.05\right]$ and contralateral trials $\left[F(1,17)=15.16, M S_{\mathrm{e}}=1,384.48\right.$, $p<.01]$. The facilitation effect at the shorter SOA was significant only for contralateral trials $[F(1,17)=42.15$, $\left.M S_{\mathrm{e}}=372, p<.001\right]$. Second, the Simon effect was present only for uncued trials at the shorter $(29-\mathrm{msec})$ SOA $\left[F(1,17)=7.65, M S_{\mathrm{e}}=940.08, p<.05\right]$ and only for cued trials at the longer $(23-\mathrm{msec}) \mathrm{SOA}[F(1,17)=$ $\left.6.83, M S_{\mathrm{e}}=607.68, p<.05\right]$.

In the error analysis, only the SOA $\times$ cuing interaction approached significance $\left[F(1,17)=4.3, M S_{\mathrm{e}}=16.14\right.$, $p=.0535]$. However, neither the facilitation effect $(1.95 \%$ errors) nor the IOR at the longer SOA $(-0.84 \%$ errors) was significant. When misses and mistakes were analyzed separately, no effect was significant.

\section{Discussion}

Again, the IOR effect was obtained with both the detection and the discrimination tasks. The three-way interaction of task $\times$ SOA $\times$ cuing did not approach significance $(p>.8)$. IOR was of similar magnitude for both tasks ( -34 and $-41 \mathrm{msec})$. Nor was there any sign of decrease in IOR in the discrimination task in comparison with that observed in the previous experiment. In fact, it was numerically larger in the present experiment.

Regarding the robustness of IOR with the discrimination task, we should mention that we have obtained results similar to those reported here in an experiment without catch trials: -28 -msec IOR $(-2.34 \%$ errors $)$ at a 1,000 msec SOA (Lupiáñez \& Solano, in press).

So, two conclusions can be drawn. First, although IOR did not appear at $400 \mathrm{msec}$ in the discrimination task used here, it did appear at $700 \mathrm{msec}$, and was of comparable magnitude to that observed in detection. Second, the IOR effect in our discrimination task did not begin to decrease as we moved from an SOA of $700 \mathrm{msec}$ to an SOA of $1,000 \mathrm{msec}$. Before rejecting the notion that this effect tends to decay earlier, we thought it prudent to test an even longer SOA $(1,300 \mathrm{msec})$.

\section{EXPERIMENTS 4A-4B 100- and 1,300-msec SOAs}

Two different SOAs (100 and $1,300 \mathrm{msec}$ ) and two versions of the experiment were used again: the detection task and the discrimination task. Otherwise, everything was the same as in the previous experiments.

\section{Results}

Rates of false alarms (responses to catch trials) were 0.050 and 0.014 (for short and long SOAs, respectively) in Experiment 4A and 0.078 and 0.020 in Experiment 4B. Trials with correct responses faster than $100 \mathrm{msec}$ or slower than $1,200 \mathrm{msec}(1.07 \%$ of correct response trials), as well as incorrect responses, were excluded from the RT analysis. Mean RTs and percent errors are shown in Tables 1 and 2 .

Experiment 4A: Detection task. Mean RTs for correct responses were submitted to a repeated measures ANOVA, with SOA and cuing treated as independent variables. This analysis revealed only a significant SOA $\times$ cuing interaction $\left[F(1,17)=108.24, M S_{\mathrm{e}}=120.4, p\right.$ $<.0001]$. Further analysis of the interaction revealed that both the facilitation effect at the shorter (22-msec) SOA, and the IOR effect at the longer $(-32-\mathrm{msec})$ SOA were significant $\left[F(1,17)=28.19, M S_{\mathrm{e}}=157.83, p<.0001\right.$, and $F(1,17)=56.96, M S_{\mathrm{e}}=157.17, p<.0001$, respectively]. Also, responses on cued trials were significantly faster at the shorter $(379 \mathrm{msec})$ than at the longer (408msec) SOA $\left[F(1,17)=14.6, M S_{\mathrm{e}}=524.17, p<.002\right]$, and responses on uncued trials were significantly slower at the shorter SOA $[401$ vs. $377 \mathrm{msec} ; F(1,17)=19.22$, $\left.M S_{\mathrm{e}}=284.56, p<.001\right]$. So, in this experiment the usual facilitation and IOR effects were replicated again with the detection task.

In the corresponding analysis of error percentages, there was a significant main effect of cuing $[F(1,17)=$ 
5.3, $\left.M S_{\mathrm{e}}=18.91, p<.05\right]$. Performance on cued trials was less accurate than on uncued trials $(5.48 \%$ vs. $3.12 \%$ errors). The main effect of SOA was marginally significant $\left[F(1,17)=4.3, M S_{\mathrm{e}}=13.64, p=.0536\right]$, with more errors being made at the $1,300-\mathrm{msec}$ SOA.

Experiment 4B: Discrimination task. Mean RTs for correct responses in the discrimination task were submitted to a repeated measures ANOVA, with compatibility ( 2 levels), SOA ( 2 levels), and cuing (2 levels) treated as independent variables. This analysis revealed a significant main effect of SOA $\left[F(1,17)=4.83, M S_{\mathrm{e}}=\right.$ $2,534.6, p<.05]$ and significant SOA $\times$ cuing and compatibility $\times$ cuing interactions $\left[F(1,17)=16.33, M S_{\mathrm{e}}=\right.$ $865.2, p<.001$, and $F(1,17)=7.4, M S_{\mathrm{e}}=1,694.7, p<$ .02 , respectively].

Analysis of the SOA $\times$ cuing interaction revealed a facilitation effect $(24 \mathrm{msec})$ that was significant at the shorter SOA $\left[F(1,17)=10.07, M S_{\mathrm{e}}=1,045.03, p<.01\right]$. However, the IOR effect at the $1,300-\mathrm{msec}$ SOA $(-15 \mathrm{msec})$ was not significant $(p=.1232)$. Cued trials were responded to more rapidly at the shorter $(619-\mathrm{msec})$ than at the longer $(657-\mathrm{msec})$ SOA $\left[F(1,17)=14.17, M S_{\mathrm{e}}=\right.$ $1,857.84, p<.002]$. Analysis of the compatibility $\times$ cuing interaction showed that the Simon effect was present only for uncued trials, but was only marginally significant $\left[F(1,17)=3.69, M S_{\mathrm{e}}=3,649.91, p=.0715\right]$.

In the corresponding analysis of error percentages, the main effect of compatibility was marginally significant $\left[F(1,17)=3.79, M S_{\mathrm{e}}=52.9, p=.0682\right]$. The SOA $\times$ cuing interaction was significant $\left[F(1,17)=10.55, M S_{\mathrm{e}}=\right.$ $71.69, p<.01]$ due largely to the IOR effect at the 1,300 msec SOA $(-6.5 \%$ errors $)\left[F(1,17)=5.29, M S_{\mathrm{e}}=144.95\right.$, $p<.05]$. The facilitation effect at the shorter SOA $(2.64 \%$ errors) was not significant.

The analysis of both mistakes and misses showed the same pattern of results: The SOA $\times$ cuing interaction was significant for mistakes $\left[F(1,17)=8.33, M S_{\mathrm{e}}=\right.$ $30.11, p<.02]$ and marginally significant for misses $\left[F(1,17)=4.29, M S_{\mathrm{e}}=31.69, p=.0538\right]$.

\section{Discussion}

At the 1,300-msec SOA, the IOR effect was still present in the detection task, but no longer significant in the discrimination task. From the $1,000-$ to the $1300-\mathrm{msec}$ SOA, the IOR effect in the discrimination task was reduced by more than half its original size. Thus, there appears to be another difference between detection and discrimination tasks with regard to temporal parameters. In discrimination tasks, IOR not only appears later but also seems to disappear before it does in detection tasks.

However, there are problems with this interpretation. First, the -15 -msec IOR obtained with the 1,300 -msec SOA, though not significant on its own, did not differ significantly from either the -34 effect obtained at the 700 msec SOA or from the $-31-\mathrm{msec}$ IOR obtained at the $1,000-\mathrm{msec}$ SOA (both $p \mathrm{~s}>.10$ ). Furthermore, when only the longer SOAs of Experiments 2, 3, and 4 were considered for analysis (i.e., 700-, 1,000-, and 1,300-msec
SOAs), the three-way interaction of cuing $\times$ SOA $\times$ task was not significant $[F(1,102)<1]$. Second, and more important, though IOR was not significant at the 1,300msec SOA in the RT analysis, it was significant in the analysis of error percentages. Therefore, after an SOA of $700 \mathrm{msec}$, the data seem to show a very similar pattern for the detection and the discrimination tasks.

Another experiment was conducted to rule out the possibility that eye movements could explain the pattern of data in the discrimination task.

\section{EXPERIMENTS 5A-5B Eye Movement Monitoring}

So far it has been shown that IOR can be consistently obtained in a color discrimination task (choice RT). Another important finding in the previous set of experiments was that, even though IOR was obtained in both the detection and the discrimination tasks, the time course seems to be different for each task. It could be argued that, given that discrimination could be more difficult than detection, subjects could try to foveate the target before responding in the discrimination task, but not in the detection task. If this were the case, the IOR found in the discrimination task could be more related to eye movements than to the attentional modulation of perceptual representations. This alternative explanation would be more challenging for the differences found in time course. It could be argued that if performance in the discrimination task were based on saccade execution, by the 400 -msec SOA, subjects would have had no time to return the eyes to the fixation point (or to the opposite box). Only with longer SOAs would there be enough time to first fixate the cued box and then refixate the uncued one, so that at the 400-msec SOA, facilitation instead of IOR would be found.

Nonetheless, we think that this is unlikely. If subjects found it helpful to foveate the target before responding, they would try to fixate it before its appearance. Note, however, that the target was displayed for only $33 \mathrm{msec}$. Then, subjects would try to anticipate the target by fixating the cued box, and there is no reason to think that they would change fixation to the opposite box before the target has appeared. Furthermore, subjects would not find it helpful to try to fixate the target using the cue for the following reason. On $50 \%$ of the trials in every experiment, the SOA plus target duration $(133 \mathrm{msec})$ was too short for subjects to fixate the target before it disappeared. In the remaining $50 \%$ of the trials (long SOA), they could obtain valid information only in half the trials. Thus, the information provided by the cue could only be used to fixate the target in $25 \%$ of the trials (long SOA, cued trials). That should have been sufficient to discourage subjects from anticipating the target. That was confirmed by experimenters' and subjects' impressions: When they were moving the eye, the task was very difficult.

Nevertheless, we replicated Experiments $1 \mathrm{~B}$ and 3B with eye movement monitoring in order to reject any pos- 
sible implication of saccadic performance in our conclusions. We replicated these experiments because they represent the two most valuable pieces of information of this research-that IOR can be obtained in the discrimination task and that the effect is not present with the 400 msec SOA in this task.

\section{Method \\ Subjects. Twelve subjects from the same pool used in the previ- ous experiments participated. Six subjects participated in Experi- ment $5 \mathrm{~A}$, and the other 6 subjects participated in Experiment $5 \mathrm{~B}$. All subjects had normal vision. \\ Apparatus, Stimuli, Procedure, and Design. Experiment 5A was the same as Experiment $1 \mathrm{~B}$ and Experiment $5 \mathrm{~B}$ was the same as Experiment $3 \mathrm{~B}$, except that eye movements were monitored. Subjects were run individually and their eye position was monitored using the Model 210 eye tracker from Applied Science Laborato- ries. When an eye movement was detected, a code was introduced to eliminate that trial and a message asking subjects to keep their eyes fixated on the fixation point was displayed. Otherwise, every- thing else was the same as in the corresponding experiment: In Ex- periment $5 \mathrm{~A}$, the SOA values were 100 and $400 \mathrm{msec}$, and in Ex- periment $5 \mathrm{~B}$, they were 100 and $1,000 \mathrm{msec}$.}

\section{Results and Discussion}

Rates of false alarms (responses to catch trials) were 0.125 and 0.166 (for short and long SOAs, respectively) in Experiment $5 \mathrm{~A}$ and 0.000 and 0.000 in Experiment $5 \mathrm{~B}$. Subjects moved their eyes from fixation in $2.5 \%$ of the trials in Experiment $5 \mathrm{~A}$ and $0.94 \%$ in Experiment 5B. Trials with correct responses faster than $100 \mathrm{msec}$ or slower than $1,200 \mathrm{msec}(1.22 \%$ and $0.33 \%$ of correct response trials for Experiments $5 \mathrm{~A}$ and $5 \mathrm{~B}$, respectively), trials in which an eye movement was made, as well as incorrect responses, were excluded from the RT analysis. Mean RTs and percent errors are shown in Table 3.

\section{Experiment 5A: 100- and 400-msec SOAs}

Mean RTs for correct responses were submitted to a repeated measures ANOVA, with compatibility (2 levels), SOA ( 2 levels), and cuing ( 2 levels) treated as independent variables. This analysis revealed a significant main effect of both compatibility $\left[F(1,5)=7.41, M S_{\mathrm{e}}=\right.$ $772.2, p<.05]$ and cuing $\left[F(1,5)=10.83, M S_{\mathrm{e}}=1,309.0\right.$, $p<.05]$. The interaction between these two variables was also significant $\left[F(1,5)=19.05, M S_{\mathrm{e}}=170.1, p<.01\right]$ due to the fact that the Simon effect observed with cued trials $\left(38 \mathrm{msec} ; F(1,5)=15.92, M S_{\mathrm{e}}=552.1, p<.02\right]$ vanished with uncued trials $(5 \mathrm{msec})$. This pattern of results is similar to that found by Possamaï (1990) in a detection task in which the target was to be detected in half the trials by hitting an ipsilateral key and by hitting a contralateral key in the other half. However, in Experiment $1 \mathrm{~B}$, there was no trend for that interaction, and the pattern is opposite to the one found in our Experiment 4B and at the short SOA of Experiment 3B. Thus, more research is necessary to clear up these inconsistencies in the effect of cuing on the Simon effect.

More interesting, there was no sign of an SOA $\times$ cuing interaction $(p=.6256)$. So, we replicated the previous result, in which the effect of cuing was still positive by the $400-\mathrm{msec}$ SOA. This effect cannot be due to the eye movements because those were excluded.

In the corresponding analysis of error percentages, only the three-way interaction was significant $[F(1,5)=20.09$, $\left.M S_{\mathrm{e}}=4.93, p<.01\right]$, which resulted from the fact that the Simon effect was reversed in the invalid trials at the short SOA (the same result was obtained in the analysis of mistakes, and no effect was significant in the analysis of misses).

\section{Experiment 5B: 100- and 1,000-msec SOAs}

Mean RTs for correct responses were submitted to a repeated measures ANOVA, with compatibility (2 levels), SOA (2 levels), and cuing (2 levels) treated as independent variables. Although no effect or interaction was significant, the effect of cuing ( $-25-\mathrm{msec}$ IOR) was significant at the long SOA $\left[F(1,5)=7.46, M S_{\mathrm{e}}=499.8\right.$, $p<.05]$. At the shorter SOA, the effect of cuing was positive $(+22 \mathrm{msec})$ but not significant.

No effect was significant in the error analysis. However, there was again a significant IOR effect $(-3.00 \%$ errors) at the $1,000-\mathrm{msec}$ SOA $\left[F(1,5)=9.00, M S_{\mathrm{e}}=6.0\right.$, $p<.05]$ (the same pattern occurred for both misses and mistakes).

Thus, the other important data-that is, IOR in a discrimination task with a longer SOA - was again replicated with both RT and percentage of errors, without involvement of eye movement.

\section{GENERAL DISCUSSION}

As noted, IOR is considered by some to reflect a robust property of attentional processing, having been re-

Table 3

Mean Correct Response Time (RT) and Percentage of Errors (PE) in Discrimination Task With Eye Movement Monitoring: Experiment 5 Results for Cuing and Stimulus Onset Aynchrony (SOA)

\begin{tabular}{|c|c|c|c|c|c|c|c|c|c|c|c|c|c|c|c|c|c|c|}
\hline \multirow[b]{4}{*}{ Experiment } & \multicolumn{18}{|c|}{ SOA } \\
\hline & \multicolumn{6}{|c|}{$100 \mathrm{msec}$} & \multicolumn{6}{|c|}{$400 \mathrm{msec}$} & \multicolumn{6}{|c|}{$1,000 \mathrm{msec}$} \\
\hline & \multicolumn{2}{|c|}{ Cued } & \multicolumn{2}{|c|}{ Uncued } & \multicolumn{2}{|c|}{ Effect } & \multicolumn{2}{|c|}{ Cued } & \multicolumn{2}{|c|}{ Uncued } & \multicolumn{2}{|c|}{ Effect } & \multicolumn{2}{|c|}{ Cued } & \multicolumn{2}{|c|}{ Uncued } & \multicolumn{2}{|c|}{ Effect } \\
\hline & RT & $\mathrm{PE}$ & RT & PE & RT & $\mathrm{PE}$ & RT & $\mathrm{PE}$ & RT & $\mathrm{PE}$ & RT & $\mathrm{PE}$ & RT & $\mathrm{PE}$ & RT & $\mathrm{PE}$ & RT & PE \\
\hline $5 \mathrm{~A}$ & 617 & 5.67 & 654 & 4.58 & 38 & -1.08 & 618 & 2.50 & 649 & 3.33 & 31 & 0.83 & & & & & & \\
\hline $5 \mathrm{~B}$ & 618 & 5.83 & 641 & 5.00 & 22 & -0.83 & & & & & & & 633 & 3.83 & 608 & 0.83 & -25 & -3.00 \\
\hline Total & 618 & 5.75 & 648 & 4.79 & 30 & -0.96 & 618 & 2.50 & 649 & 3.33 & 31 & 0.83 & 633 & 3.83 & 608 & 0.83 & -25 & -3.00 \\
\hline
\end{tabular}


ported with both manually recorded detection time and eye movement latency as dependent variables. However, others have argued that IOR is limited to detection and localization tasks, due to several failures to obtain IOR in discrimination tasks. As a result, both the generality of IOR (Terry et al., 1994) and its importance to attentional processing (Schmidt, 1996) have been questioned. The experiments presented in this article, together with other data that we have reported elsewhere (Lupiáñez, 1996; Lupiáñez et al., 1996; Lupiáñez \& Solano, in press), demonstrate clearly that IOR can be observed in a discrimination task. Furthermore, we believe that there is sufficient evidence to support the conclusion that, although IOR may be obtained in both detection and discrimination tasks, its time course differs for these tasks.

We do not in the present data have any definitive explanation for the different time course observed in detection and discrimination tasks. However, we entertain the following speculation. It has been reported that two different representations could be activated by the attentional cuing procedure (one location based and the other object based; Abrams \& Dobkin, 1994; Tipper et al., 1994), which would lead to location- and object-based IOR. Tipper and Weaver (in press) found that the time course of object-based IOR seems to differ from that of location-based IOR; in particular, it seems to decay faster. In their experiment, SOAs of $598,1,054$, and 3,560 msec were used. Whereas location-based IOR did not interact with SOA, the object-based effect decreased significantly across SOAs $(-31,-15$, and $-1 \mathrm{msec})$.

On the other hand, we suggest that an object-based representation is relevant for discriminating a target but not for detecting it, whereas a location-based representation would be more relevant for detection. The data from Tipper and Weaver (in press) suggest that these two representations have a different facilitation-inhibition time course. It could be that the object-based representation not only loses inhibition faster than the location-based one, but also accrues inhibition more slowly. Thus, facilitation might be observed at the short $(100-\mathrm{msec})$ SOA in both tasks because both representations (location- and object-based) are activated. However, $400 \mathrm{msec}$ after the cue, the location-based representation would be inhibited, but the object-based representation would still be activated. The effect would then be inhibitory in the task to which the location-based representation is more relevant (detection task) but facilitatory in the one to which the object-based representation is more relevant (the discrimination task). Within the 700- to 1,000 -msec range, both representations would be inhibited, so performance in both tasks would show IOR. We acknowledge that this hypothesis, although interesting, is highly speculative. However, it could be helpful to guide new experiments addressing the issue of the different time course observed for IOR in detection and discrimination tasks.

In the remainder of this discussion, we explore in more detail the differences observed in the experimental literature between detection and discrimination tasks with re- gard to IOR and conclude with a discussion of the attentional basis of the IOR effect.

\section{IOR With Discrimination Tasks}

As far as we know, all previous attempts to obtain IOR in discrimination tasks, other than those requiring localization, have failed (Egly et al., 1992; Kingstone \& Gazzaniga, 1992, reported in Klein \& Taylor, 1994; Pontefract \& Klein, 1988, reported in Klein \& Taylor, 1994; Tanaka \& Shimojo, 1996; Terry et al., 1994). In contrast, the set of experiments reported here demonstrates that IOR may be obtained in both detection and discrimination tasks. Figure 2 depicts the general pattern of the cuing effect across SOA for both detection and discrimination tasks. This figure makes it clear that the only important (and significant) difference between the IOR effects obtained in the two tasks is that, at the $400-\mathrm{msec}$ SOA, IOR is observed in the detection task, whereas facilitation is observed in the discrimination task.

This difference may explain why some researchers have failed to obtain IOR in discrimination tasks. For example, Pontefract and Klein (1988, reported in Klein \& Taylor, 1994) conducted three experiments to compare the attentional effects observed in detection and discrimination tasks. In the simple RT task, subjects were to detect a sudden change in target size (expansion or contraction), and in the choice RT task, subjects were to discriminate the size change and to hit one key when the target expanded and another when it contracted. They used two SOAs, 100 and $500 \mathrm{msec}$, and obtained facilitation at the shorter SOA for both tasks. However, at the longer SOA, facilitation was observed in the discrimination task, and IOR was observed in the detection task. These results are in accord with our data. In our discrimination task, we obtained a facilitation effect at an SOA $(400 \mathrm{msec})$ that was similar to the longer of the two used by Pontefract and Klein. Our data also suggest that, had a longer SOA been used by Pontefract and Klein, the task dissociation they reported might not have occurred.

We cannot currently explain why other researchers (Egly et al., 1992; Tanaka \& Shimojo, 1996; Terry et al., 1994) did not find IOR with discrimination tasks. There are many dissimilarities between their experiments and the ones reported here - target-target versus cue-target paradigm, color discrimination versus letter discrimination, temporal uncertainty (SOA manipulation within a block of trials), longer SOAs, location markers, and so on. Some of these differences could explain why IOR was not obtained with the procedures they used. In our laboratory, we have obtained IOR in several discrimination tasks (color, shape, and direction discrimination) and by manipulating SOA between blocks and within a block (temporal uncertainty). Thus, we think that the main difference to explain the discrepancies between our data and those of Terry et al. (1994) and Tanaka and Shimojo (1996) is the procedure used: target-target in their papers and cue-target in all of our experiments. Further research is necessary to clear up this issue. 


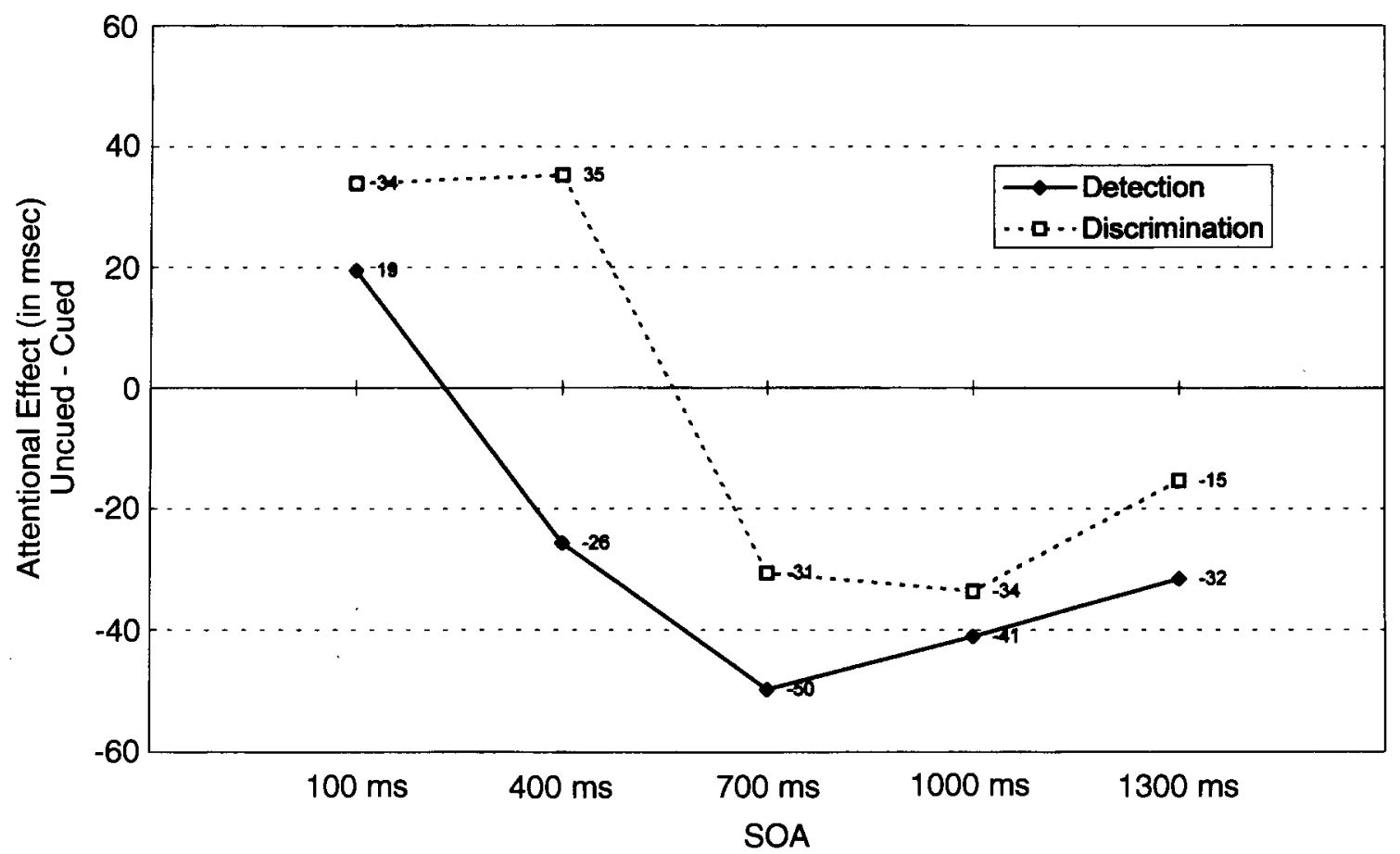

Figure 2. The time course of cuing effects (facilitation and inhibition of return) for detection and discrimination tasks. Mean response time differences in milliseconds between uncued and cued trials are represented on the ordinate axis. At the 100-msec stimulus onset asynchrony, the data were collapsed across Experiments 1-4.

\section{Attentional Nature of the IOR Effect}

Failures to obtain IOR with discrimination tasks have also been used to argue against the attentional nature of the effect. Schmidt (1996) described the IOR effect as acting on visual-motor representations, given "that little direct evidence exists that IOR acts on perceptual representations" (p. 896). Klein and Taylor (1994) favor an explanation of IOR as a kind of bias against responding to events appearing in a previously cued location. However, Reuter-Lorenz et al. (1996) have recently reported several experiments supporting the attentional nature of the IOR effect. From our point of view, data from our paper also support the attentional nature of IOR.

First, IOR was obtained consistently in our discrimination task at SOAs longer than $400 \mathrm{msec}$. Thus, the argument that IOR is limited to detection and localization tasks is simply not valid, at least with the procedure used here. Second, if IOR reflects a response bias rather than inhibition of perceptual representations, responses to previously cued locations might be slower, but not less accurate. Yet, we observed IOR in measures of error as well as RT (see Figure 3).

Although we did not observe IOR in the error data in all experiments, this is very likely due to the limited power of those statistical tests. To overcome this problem, we conducted an ANOVA pooling error percentage data across Experiments $2-4 .{ }^{4}$ This analysis revealed a highly significant SOA $\times$ cuing interaction $(p<.0001)$. Indeed, the IOR effect was highly significant for both detection $(-3.01 \% ; p<.005)$ and discrimination $(-3.47 \% ; p<$
$.002)$. In the discrimination task, the IOR was significant for both mistakes $(-1.57, p<.05)$ and misses $(-1.90$, $p<.02)$. The facilitation effect at the shortest SOA was significant only in the discrimination task $(+2.36 \%$; $p<$ $.001)$, and this was mainly due to mistakes $(+2.13 ; p<.01)$.

Thus, it is clear that responses to targets presented at previously cued loci not only were slower but were also less accurate at SOAs of $700 \mathrm{msec}$ or longer. If perceptual processes did not underlie this cuing effect, then accuracy should not have been affected. We assume that the larger error rate (misses and mistakes) in the cued trials and longer SOA was due to an attentional inhibition (IOR) of the perceptual representation of this object and/or location. Therefore, this set of experiments supports the view that IOR has an attentional basis.

Two considerations should be made here with regard to accuracy data: First, there are no consistent IOR differences between detection and discrimination, and second, in the detection task, the effect seems to have appeared later than with RT data (700-msec SOA). At the 400-msec SOA, the effect was positive for both tasks, but significant only for discrimination.

$A$ last point concerns the relation between IOR in choice RT and the Simon effect. If IOR was a bias against responding toward the cued location at long SOAs, cuing should interact with compatibility (more precisely, IOR should be obtained only in ipsilateral trials). As can be observed, the pattern of results regarding compatibility and cuing is not consistent from one experiment to another. In order to increase the power of the analysis, we analyzed the 


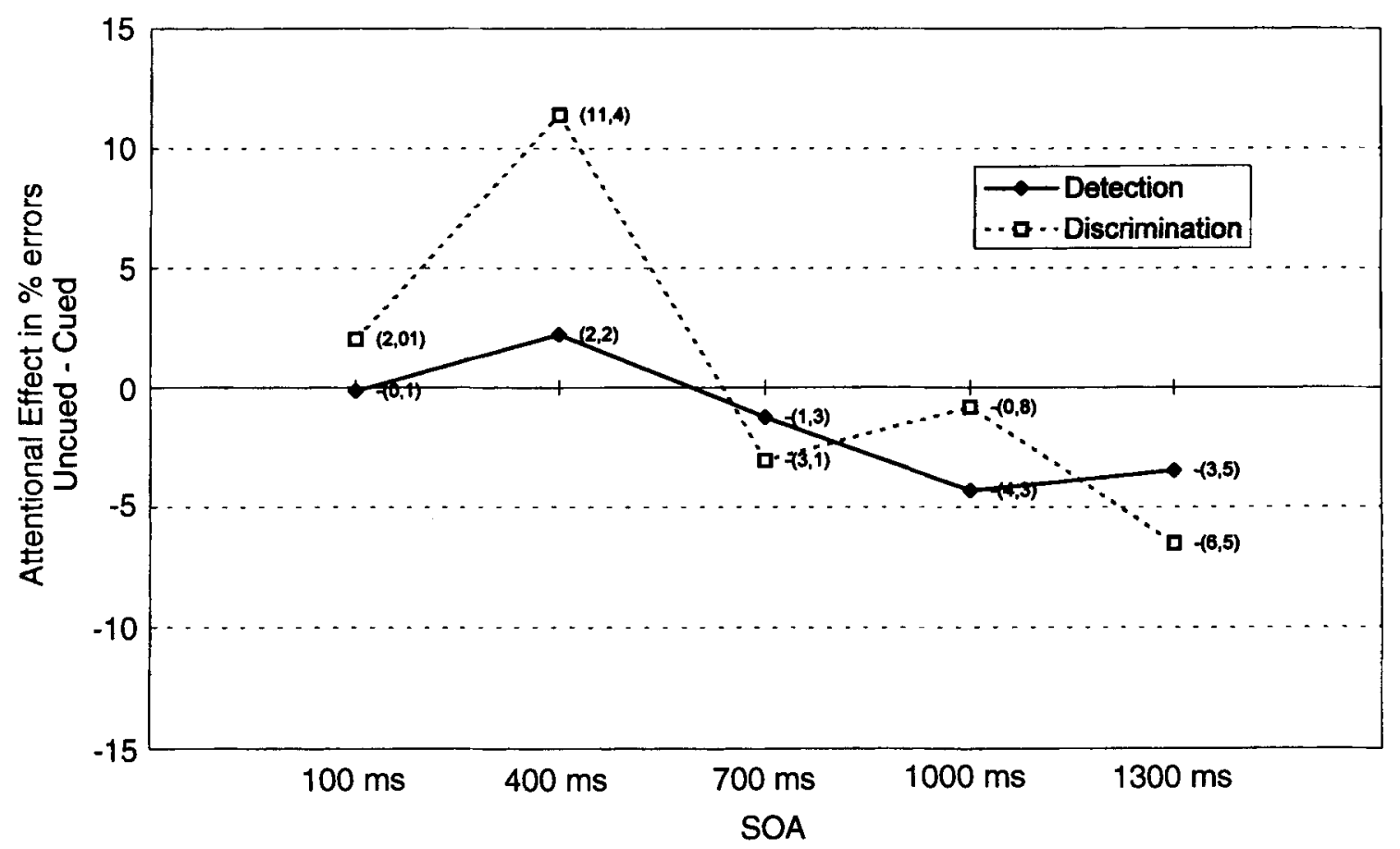

Figure 3. The time course of cuing effects (facilitation and inhibition of return) for detection and discrimination tasks. Differences in error percentage for uncued and cued trials are represented on the ordinate axis at the 100-msec stimulus onset asynchrony, the data were collapsed across Experiments 1-4.

data from the longest SOA of all the main experiments in which we obtained IOR in the discrimination task (Experiments $2 \mathrm{~B}, 3 \mathrm{~B}$, and $4 \mathrm{~B}$ ) to test this hypothesis. In neither the RT nor the error analysis did the compatibility $\times$ cuing interaction approach significance ( $-25 \mathrm{msec},-4.91 \% \mathrm{er}-$ rors for ipsilateral trials; $-29 \mathrm{msec},-2.04 \%$ errors for contralateral trials). Thus the pattern of data suggests that the IOR effect observed in the experiments reported here is not related to response biases.

To summarize, we observed a consistent pattern of IOR in a discrimination task, that seems to be independent of the compatibility of the response to be made. This effect argues against recent conjecture that IOR may not be a robust and general empirical phenomenon. Importantly, the temporal pattern of the IOR effect appears to depend on the task. In our discrimination task, IOR was observed only at SOAs longer than $400 \mathrm{msec}$. The different time courses of IOR in detection and discrimination may have resulted in the previous failure to observe IOR in discrimination tasks. Other failures to observe IOR in discrimination may be attributable to other methodological differences. To understand the basis of IOR, a systematic investigation of such differences will be required.

\section{REFERENCES}

Abrams, R. A., \& Dobkin, R. S. (1994). Inhibition of return: Effects of attentional cuing on eye movement latencies. Journal of Experimental Psychology: Human Perception \& Performance, 20, 467-477.

Egly, R. Rafal, R. D., \& HeniK, A. (1992, November). Reflexive and voluntary orienting in detection and discrimination tasks. Paper presented at the annual meeting of the Psychonomic Society, St. Loujs. HOMMEL, B. (1995). Stimulus-response compatibility and the Simon effect: Toward an empirical clarification. Journal of Experimental Psychology: Human Perception \& Performance, 21, 764-775.

KLEIN, R. M., \& TAYLOR, T. L. (1994). Categories of cognitive inhibition with reference to attention. In D. Dagenbach \& T. H. Carr (Eds.), Inhibitory mechanisms in attention, memory and language (pp. 113150). New York: Academic Press.

LUPIÁÑ̃E, J. (1996). Location- and color-based IOR in detection and discrimination task. Manuscript in preparation.

Lupiáñez, J., Milán, E. G., Tornay, F., \& Tudela, P. (1996, September). Inhibition of return with detection and discrimination tasks: Differences in time course. Paper presented at the VIII Congreso de la Sociedad Española de Psicología Comparada, Málaga, Spain.

Lupiáñez, J., \& SOlano, C. (in press). Inhibición de retorno en una tarea de discriminación de color: No interacción con el efecto Simon [Inhibition of return in a color discrimination task: No interaction with the Simon effect]. Cognitiva.

Lupiáñez, J., ToRnay, F., \& Tudela, P. (1996, September). Locationbased IOR: A different time course for detection and discrimination task. Paper presented at the IX Congress of the European Society for Cognitive Psychology (ESCOP), Würzburg.

MAYLOR, E. A. (1985). Facilitatory and inhibitory components of orienting in visual space. In M. I. Posner \& O. S. M. Marin (Eds.), Attention and performance $X I$ (pp. 189-207). Hillsdale, $\mathrm{NJ}$ : Erlbaum.

Müller, H. J., \& Mühlenen, A. von. (1996). Attentional tracking and inhibition of return in dynamic displays. Perception \& Psychophysics, 58, 224-249.

POSNER, M. I. (1980). Orienting of attention. Quarterly Journal of Experimental Psychology, 32, 3-25.

POSNER, M. I., \& COHEN, Y. (1984). Components of visual orienting. In H. Bouma \& D. G. Bouwhuis (Eds.), Attention and performance $X$ (pp. 531-556). Hillsdale, NJ: Eribaum.

Possamaï, C. A. (1990). A responding hand effect in a simple-RT pre- 
cueing experiment: Evidence for a late locus of facilitation. Acta Psychologica, 77, 47-63.

PratT, J. (1995). Inhibition of return in a discrimination task. Psychonomic Bulletin \& Review, 2, 117-120.

Rafal, R. D., Calabresi, P. A., Brennan, C. W., \& Sciolto, T. K. (1989). Saccade preparation inhibits reorienting to recently attended locations. Journal of Experimental Psychology: Human Perception \& Performance, 15, 673-685.

Reuter-Lorenz, P. A., JHA, A. P., \& Rosenquist, J. N. (1996). What is inhibited in inhibition of return? Journal of Experimental Psychology: Human Perception \& Performance, 22, 367-378.

Schmidr, W. C. (1996). Inhibition of return is not detected using illusory line motion. Perception \& Psychophysics, 58, 883-898.

SCHNEIDER, W. (1988). Micro Experimental Laboratory: An integrated system for IBM PC compatibles. Behavior Research Methods, Instruments, \& Computers, 20, 206-217.

Simon, J. R. (1969). Reactions toward the source of stimulation. Journal of Experimental Psychology, 81, 174-176.

Simon, J. R., \& RUdell, A. P. (1967). Auditory S-R compatibility: The effect of an irrelevant cue on information processing. Journal of $\mathrm{Ap}$ plied Psychology, 51, 300-304.

TANAKa, Y., \& Shimojo, S. (1996). Location vs. feature: Reaction time reveals dissociation between two visual functions. Visual Research, 36, 2125-2140.

Terry, K. M., Valdes, L. A., \& Neill, W. T. (1994). Does “inhibition of return" occur in discrimination tasks? Perception \& Psychophysics, $55,279-286$.

Tipper, S. P., Driver, J., \& Weaver, B. (1991). Object-centered inhibition of return of visual attention. Quarterly Journal of Experimental Psychology, 43A, 289-298.

TIPPER, S. P., \& WEAVER, B. (in press). The medium of attention: Locationbased, object-centered or scene-based? In R. Wright (Ed.), Visual attention. New York: Oxford University Press.

Tipper, S. P., Weaver, B., Jerreat, L. M., \& Burak, A. L. (1994). Object-based and environment-based inhibition of return of visual at- tention. Journal of Experimental Psychology: Human Perception \& Performance, 20, 478-499.

UMILTÀ, C., \& NicOLETTI, R. (1992). An integrated model of the Simon effect. In J. Alegria, D. Holender, J. Junça de Morais, \& M. Radeau (Eds.), Analytic approaches to human cognition (pp. 331-350). Amsterdam: North-Holland.

\section{NOTES}

1. Catch trials were excluded from all the main analyses of both RT and errors. Only percentage of responses to catch trials (false alarms) are reported. False alarm percentages of the eight experiments were introduced to a $2(\mathrm{SOA}) \times 2$ (task) $\times 4$ (experiment) mixed analysis of variance, with SOA as a within-subjects variable and task and experiment as a between-subjects variable (note that the compatibility and cuing variables have no sense when no target is displayed). Only the main effect of SOA (short/long) was significant $\left[F(1,136)=10.59, M S_{\mathrm{e}}=30.5\right.$, $p<.002]$, due to the higher rate at the shorter SOA ( $4.4 \%$ vs. $2.3 \%)$. Neither task nor experiment (value of the longer SOA) interacted with SOA.

2. In the detection task, errors refer to misses (no response on no-catch trials). In the discrimination task, there are two kind of errors: misses (as in the detection task) and mistakes (incorrect responses). Both misses and mistakes were analyzed separately and collapsed to increase the power. The two kinds of errors are reported separately, together with the compatibility variable data, in the Appendix.

3. A previous analysis showed no effect of compatibility and no interaction with other variables. This is as it should be, because this variable had no meaning for the detection task and was only coded for the sake of control. Thus data were collapsed across this variable.

4. The compatibility variable was excluded from this analysis because it was not relevant to the issue we wanted to explore. Data from the first experiment were also excluded, because the effect was always positive for both tasks and SOAs, but significant only for the discrimination task at the $400-\mathrm{msec} \mathrm{SOA}$. 


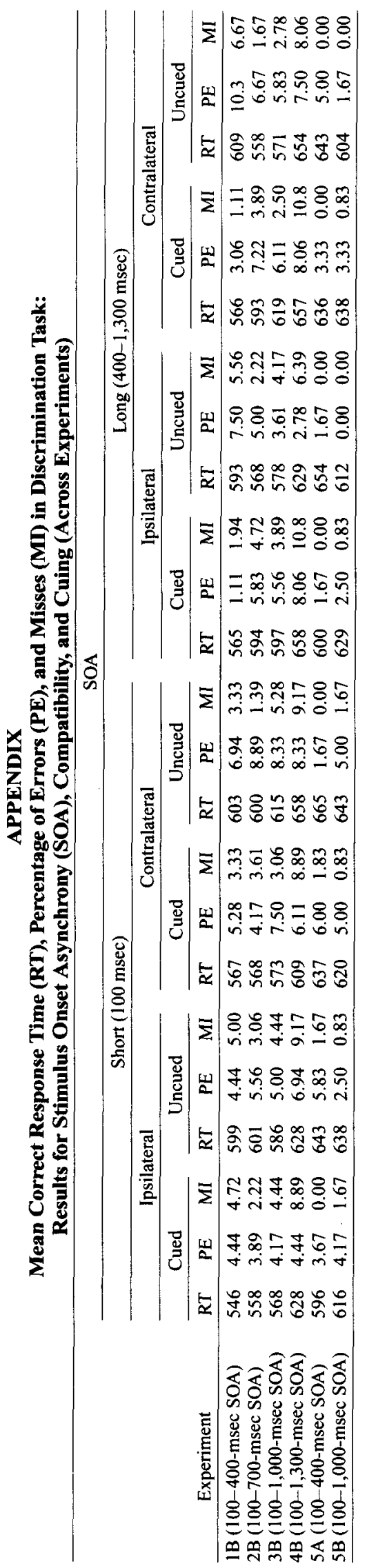

